\title{
In Reminiscence of Dr. Leon Gabriel (1937-2020), Distinguished Cardiologist in Shiraz, Iran
}

\author{
Mohammad Hossein Azizi MD ${ }^{1^{*}}$ \\ ${ }^{1}$ Academy of Medical Sciences of the I.R. of Iran, Tehran, Iran.
}

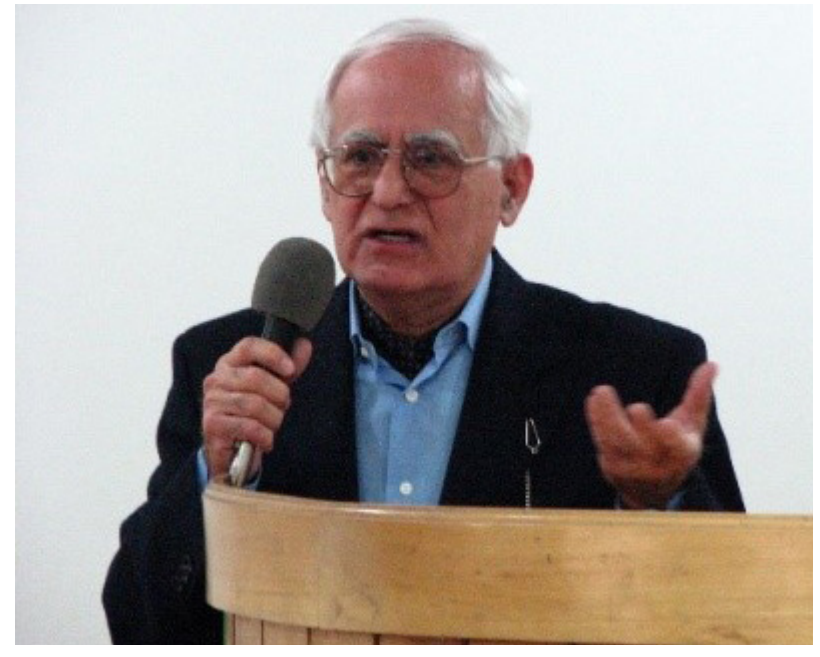

Dr. Leon Gabriel (1937-2020).

With profound sadness, Dr. Leon Gabriel, an expert cardiologist who practiced over three decades in Shiraz, Fars province, passed away in August 2020 at the age of 83 in the USA, due to pulmonary cancer. His demise is a loss for his family, colleagues and patients in Shiraz.

Leon Gabriel was born to an Armenian family in a small village called Qareh Guz in Urmia, West

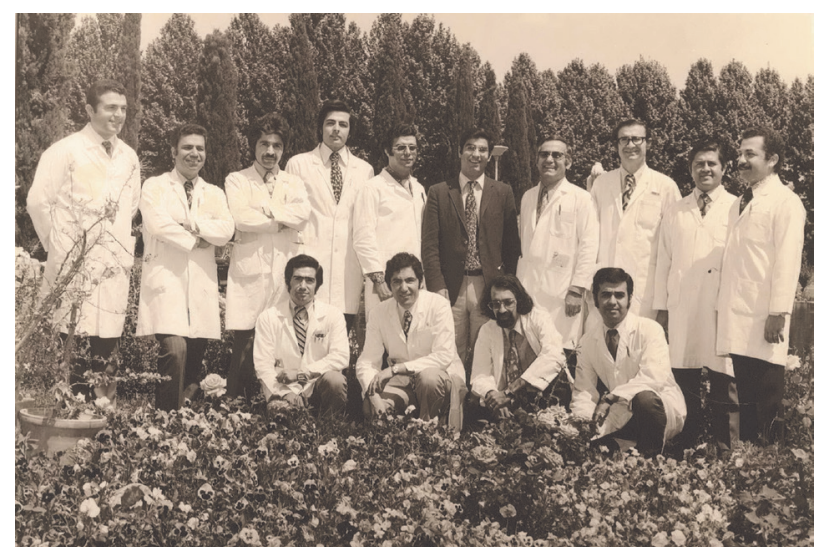

Professors and residents of the Internal Medicine Department of the Shiraz University School of Medicine, Nemazee Hospital,1973. Dr. Gabriel is the fourth standing person from right.
Azerbaijan Province of Iran. When he was a child, his family immigrated to Tehran, where Leon completed his elementary and high school education. In due course, he went to Europe to continue his training and entered a medical school in Austria. He married Miss Arax while he was in his internship period. The young Leon, having successfully completed his medical education and received his MD degree, returned to Iran.

On his return, after serving his military duty in the Health Corps (Sepah-e Behdasht), Dr. Gabriel enrolled in the internal medicine residency program at the Shiraz School of Medicine in 1969. Later, he continued his training as a fellow of cardiology. In April 1977, he published an article entitled "Acute Granulomatous Pericarditis" which was published in the CHEST journal. ${ }^{1}$

After becoming a cardiologist, Dr. Gabriel started his medical career in his own private clinic in Shiraz, while still maintaining a close connection with the internal medicine department and actively participating in scientific meetings and grand rounds for more than 30 years. He was an influential clinician who devoted most of his fruitful life to caring for cardiac patients.

He is survived by his wife, Mrs. Arax, his two children Allen (MD, plastic surgeon) and Linda (nurse). Dr.

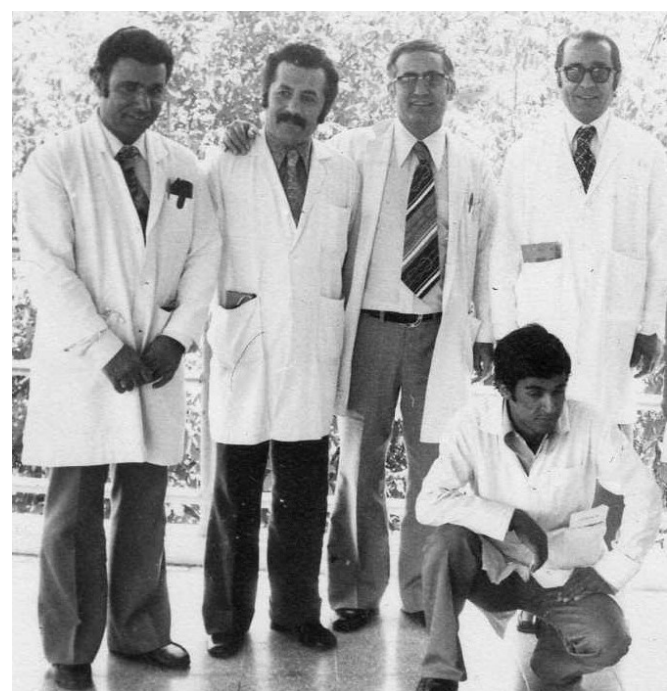

Nemazee Hospital, Shiraz, 1974; Dr. Gabriel is second from right.

*Corresponding Author: Mohammad-Hossein Azizi, MD; Academy of Medical Sciences of the I.R. of Iran, Tehran, Iran. Tel: +98-212-293-98-6. Email: azizi@ams.ac.ir 
Gabriel believed in goodness and love and as the famous Iranian poet Hafez (ca. 1315 - 1390) said, "He who lived with love never dies." His memory will be always alive and his efforts will be remembered.

\section{Conflict of Interest Disclosures}

None.

\section{Ethical Statement}

Not applicable.

\section{Acknowledgment}

I would like to thank Dr. Akbar Rajaei, former Professor of Rheumatology at the Shiraz University of Medical Sciences, and Mrs. Arax, the wife to Dr. Gabriel who provided me with the required information on Dr. Gabriel's life and career.

\section{References}

1. Gabriel L, Shelburne JC. Acute Granulomatous Pericarditis: A Clinical and Hemodynamic Correlate. CHEST. 1977;71(4): 473-8.

Received: August 18, 2020, Accepted: August 22, 2020, ePublished: August 25, 2020

Cite this article as: Azizi MH. In reminiscence of Dr. Leon Gabriel (1937-2020), distinguished cardiologist in Shiraz, Iran. Arch Iran Med. $2020 ; 23(8): 584-585$. doi: 10.34172/aim.2020.67.

(c) (c) (c) 2020 The Author(s). This is an open-access article distributed under the terms of the Creative Commons Attribution License (http://creativecommons. org/licenses/by/4.0), which permits unrestricted use, distribution, and reproduction in any medium, provided the original work is properly cited. 